\title{
Wear and Friction Behaviour of Kans Grass Fiber/Polyester Composites
}

\author{
Mukesh Kumar Mann, Vishal Ahlawat, Sunil Nain, Malkit Gir, Aman Beniwal
}

\begin{abstract}
The friction and wear behaviour of kans grass fiber (KGF) polyester composites were examined. An amount of 0,10 , $13.35,18$ and $20.08 \mathrm{vol} \%$ was reinforced into the polyester resin for composite development using hand layup technique. The tribo-test specimens of size $4 \times 4 \times 50 \mathrm{~mm}$ were cut from the fabricated composites and tested on wear and friction testing machine at 0.5-1.5 m/s of sliding velocity and a constant load of 5 $N$ for 60 seconds. It was found that the neat polyester specimen possessed less wear resistance than the KGF composites at almost all the sliding conditions. The fiber content and variation in sliding velocity slightly influenced the friction behaviour. The increase in fiber vol\% from 10 to 20.08 marginally increased the average friction coefficient of the KGF composite specimens at 0.5 $\mathrm{m} / \mathrm{s}$ and $1.5 \mathrm{~m} / \mathrm{s}$ whereas fluctuating behaviour was noticed at intermediate sliding velocity.

Keywords: friction and wear behaviour, kans grass fiber, polyester composites.
\end{abstract}

\section{INTRODUCTION}

The health and environment concerns raised the demand of natural fibers in place of synthetic fibers. Besides many other favourable properties such as low density, cheap, comparable specific strength, non-corrosive properties and easy and safe processing and manufacturing have increased their use in different applications [1]-[4]. The researchers have investigated the polymer composites reinforced with different natural fibers as an alternative to the synthetic fibers for their mechanical and tribological properties. Nowadays, automobile industries are showing keen interest toward the use of natural fiber composites due to their wide range of applications in manufacturing different parts of automobiles [5]-[8]. Ibrahim et al. [9] used palm fronds and mango`s dry leaves with polyester resin for composite fabrication and tested for friction and wear properties. The results suggested the palm fronds and mango`s dry leaves as a material of high wear resistance and high friction coefficient. Musaceae rachis fibers of different sizes were charged with polyester and examined for tribo-properties by Betancourt et al. [10]. It was observed that the decrease in fiber size increased the wear resistance as compared to the neat specimen. Nordin et al. [11] investigated the specific wear rate of kenaf polyester composites and kenaf epoxy composites using abrasion resistance machine in dry sliding conditions at $1.4 \mathrm{~m} / \mathrm{s}$ of velocity and different applied loads ranging from $5 \mathrm{~N}$ to $30 \mathrm{~N}$. The results showed that both the composites exhibited

Revised Manuscript Received on June 15, 2019.

Mukesh Kumar Mann, Mechanical Engineering Department, U.I.E.T., M.D.U., Rohtak, India.

Vishal Ahawat, Mechanical Engineering Department, U.I.E.T., Kurukshetra University, Kurukshetra, India.

Sunil Nain, Mechanical Engineering Department, U.I.E.T., Kurukshetra University, Kurukshetra, India. approximately the same wear rate. Ahlawat et al. [12] prepared specimens of sisal and jute fiber embedded with polyester resin for comparing their tribo-characteristics with the glass fiber polyester composite. It was analysed that the sliding speed followed by the filler content and fiber wt $\%$ were found the most influencing parameters in descending order. Later on, the mechanical and tribological properties of walnut shell powder reinforced polyester composites were investigated. It was suggested that the walnut shell powder can be used as a potential filler in brake friction materials application [13].

Kans grass, a waste land weed and a part of the family of sugar cane, grows up to three meters in height at river shower and agriculture land boundaries [14]. It is also considered as a valuable medical herb in traditional India and use for making traditional structure for residence storage of grains and animal feed and sitting chairs etc. In the present investigation, kans grass, is introduced as reinforcing fiber in polyester resin for the development of composites and tested for friction and wear properties.

\section{COMPOSITES PREPARATON}

The polyester resin in unsaturated form of density $1250 \mathrm{~kg} / \mathrm{m}^{3}$ was used as matrix material in which the kans grass lengthened fibers were reinforced in different vol $\%(0,10$, 13.35, 18 and 20.08). The cobalt napthanate acted as accelerator, methyl ethyl ketone peroxide acted as catalyst and polyvinyl alcohol as releasing agent. The extraction of KGF and composites preparation procedure were adopted from the previous work of Ahlawat et al. [14]. The samples of required size $(4 \mathrm{~mm} \times 4 \mathrm{~mm} \times 50 \mathrm{~mm})$ were cut from the fabricated composites for tribological testing shown in fig. 1.

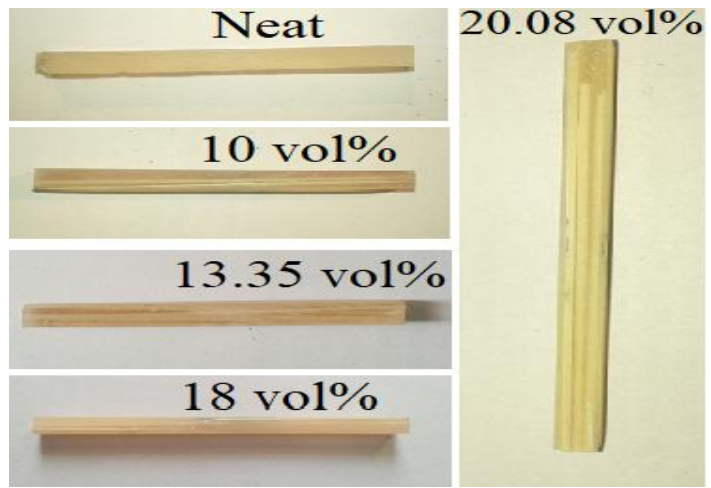

Fig. 1 Specimens prepared for tribo-testing

\section{WEAR AND \\ FRICTION TEST}

The prepared specimens 
were tested for the wear and friction study using wear and friction testing machine of make DUCOM, shown in fig. 2. The counter surface was prepared with a 1000 grit emery paper wrapped over the disc. The tests conditions, shown in table 1 , were chosen on the basis of pilot experiments. A separate track diameter was chosen for each experiment and the $\mathrm{SiC}$ paper was replaced with the new one. Before weighing and the start of the test, the specimen was cleaned properly with acetone to remove sticky material from the surface. The test machine was also connected with a computer equipped with WINDUCOM-2010 software for acquiring the friction and wear results.

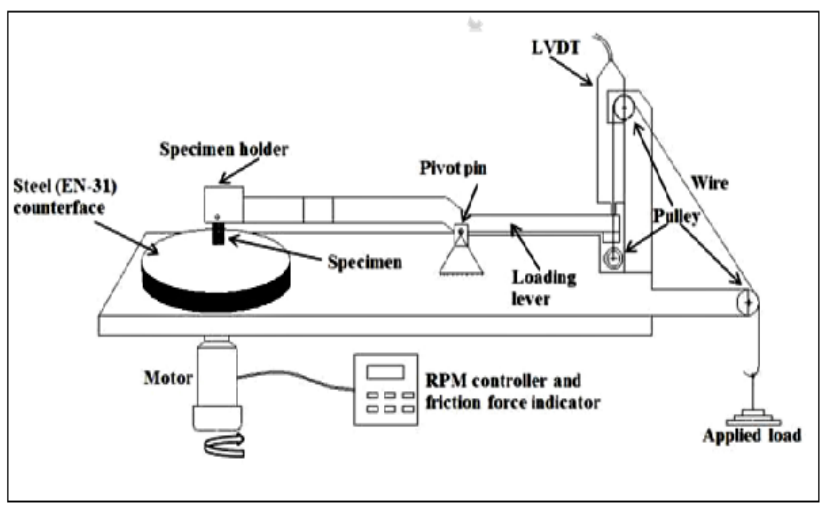

Fig. 2 Wear and friction testing machine [15]

Table I. Test conditions

\begin{tabular}{|c|c|c|c|c|}
\hline Sr. No. & $\begin{array}{c}\text { Sliding } \\
\text { speed, } \\
(\mathrm{m} / \mathrm{s})\end{array}$ & $\begin{array}{c}\text { Fiber vol. } \\
\%\end{array}$ & $\begin{array}{c}\text { Load } \\
(\mathrm{N})\end{array}$ & $\begin{array}{l}\text { Time } \\
\text { (Sec.) }\end{array}$ \\
\hline 1 & 0.5 & $\begin{array}{c}0 \\
10 \\
13.35 \\
18 \\
20.08\end{array}$ & 5 & 60 \\
\hline 2 & 1 & $\begin{array}{c}0 \\
10 \\
13.35 \\
18 \\
20.08\end{array}$ & 5 & 60 \\
\hline 3 & 1.5 & $\begin{array}{c}0 \\
10 \\
13.35 \\
18 \\
20\end{array}$ & 5 & 60 \\
\hline
\end{tabular}

\section{RESULTS AND DISCUSSION}

Fifteen experiments according to the set test conditions were performed on wear and friction testing machine. The data in terms of wear versus time, coefficient of friction versus time was recorded and analyzed. The wear behavior and coefficient of friction behavior of specimens was analyzed at $0.5,1$ and $1.5 \mathrm{~m} / \mathrm{s}$ of sliding velocity under a constant load of $5 \mathrm{~N}$ for $60 \mathrm{sec}$. and compared with the neat polyester specimen.

\section{A. Effect of Fiber Increment on wear behaviour}

Fig 3 (a) to (c) show the effect of fiber increment on wear behaviour of $\mathrm{KGF}$ composites at three different sliding velocity of $0.5 \mathrm{~m} / \mathrm{s}, 1 \mathrm{~m} / \mathrm{s}$ and $1.5 \mathrm{~m} / \mathrm{s}$.
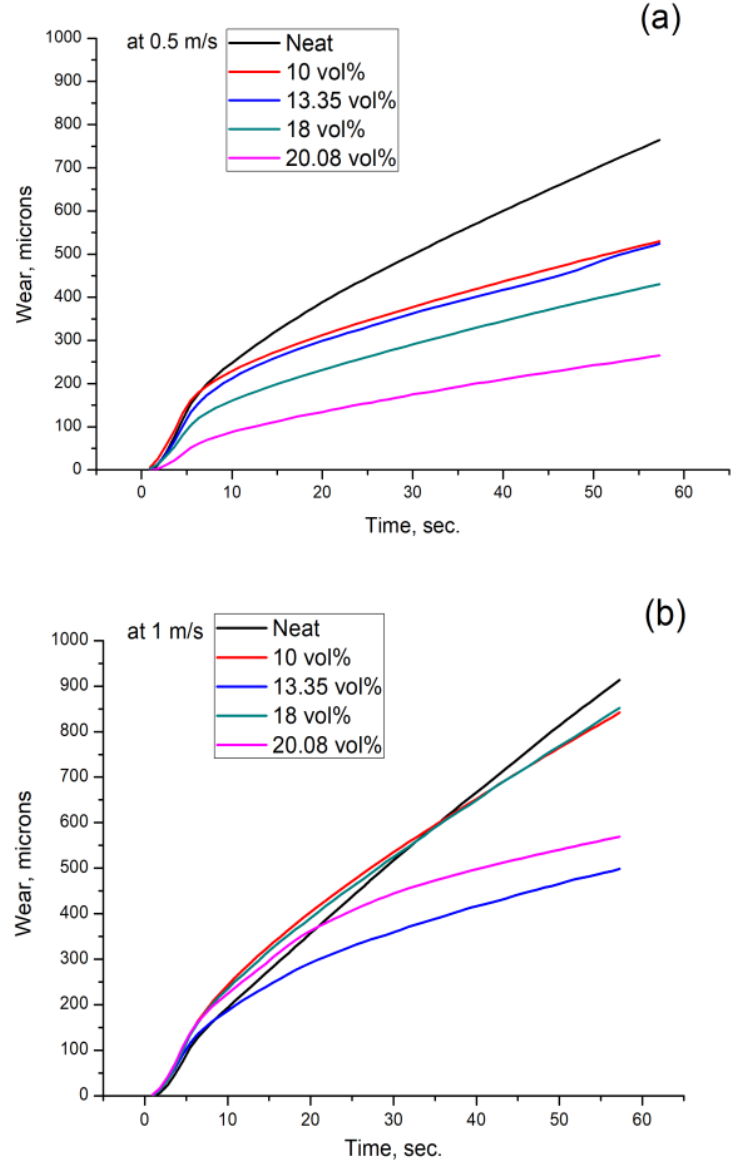

An increasing trend in wear behaviour of all the composite specimens was observed. The wear resistance of all the KGF composite specimens is more than that of the neat polyester specimen. The specimen with 20.08 fiber vol. \% showed maximum wear resistance followed by the specimen having $18,13.35$ and $10 \mathrm{vol}$. $\%$ of fiber at $0.5 \mathrm{~m} / \mathrm{s}$. This trend showed that increase in fiber vol. \% increased the wear resistance.

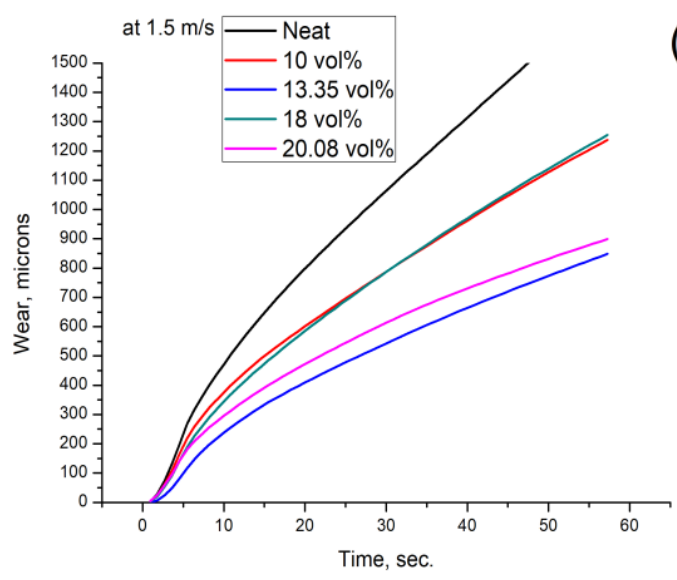

(c)

Fig. 3 Wear behavior at (a) $0.5 \mathrm{~m} / \mathrm{s}$ (b) $1 \mathrm{~m} / \mathrm{s}$ (c) $1.5 \mathrm{~m} / \mathrm{s}$

The increase in sliding velocity to $1 \mathrm{~m} / \mathrm{s}$ kept the

Published By: 
wear rate similar for the composites at $10 \mathrm{vol} \%$ and $18 \mathrm{vol} \%$. The wear behaviour of neat polyester increases initially with a lower pace up to 10 seconds then after increases linearly up to 60 seconds and attain maximum wear. The composite at 13.35 vol. \% has maximum wear resistance, followed by $20.08,18$ and 10 vol. \%. At higher velocity i.e. $1.5 \mathrm{~m} / \mathrm{s}$, the wear behaviour of all the composite specimen (10 to 20.08 vol. \%) followed the similar trend as followed by the specimens at 1 $\mathrm{m} / \mathrm{s}$ but the wear remained higher. It was also observed that the neat polyester specimen offered lesser wear resistance than the specimens prepared from fiber composites. It was also noticed that the increase in sliding velocity considerably increased the wear rate of all the specimens.

\section{B. Effect of fiber increment on coefficient of friction}

Fig 4 (a) to (c) show that the effect of fiber content variation on coefficient of friction behavior at sliding speed of $0.5 \mathrm{~m} / \mathrm{s}$, $1 \mathrm{~m} / \mathrm{s}$ and $1.5 \mathrm{~m} / \mathrm{s}$. The coefficient of friction for all the specimens attains peak within 5 seconds, then after decrease up to 20 seconds and onwards maintain approximately a constant level up to 60 seconds. This is due to the reason that the worn out particles of an emery paper as well as of the composite specimen fills into the grits and make the interface smoother. As the sliding speed increased, the peak value of coefficient of friction of all the specimens slightly increased which resulted in an increase in friction force. It is clearly seen that $13.35 \mathrm{vol}$ \% specimen has minimum coefficient of friction than neat polyester at all the sliding speeds. It was also observed that the increase in fiber content increased the coefficient of friction except at intermediate sliding velocity i.e. $1 \mathrm{~m} / \mathrm{s}$. The friction coefficient behaviour was remained more fluctuating for all the specimen at $1 \mathrm{~m} / \mathrm{s}$.
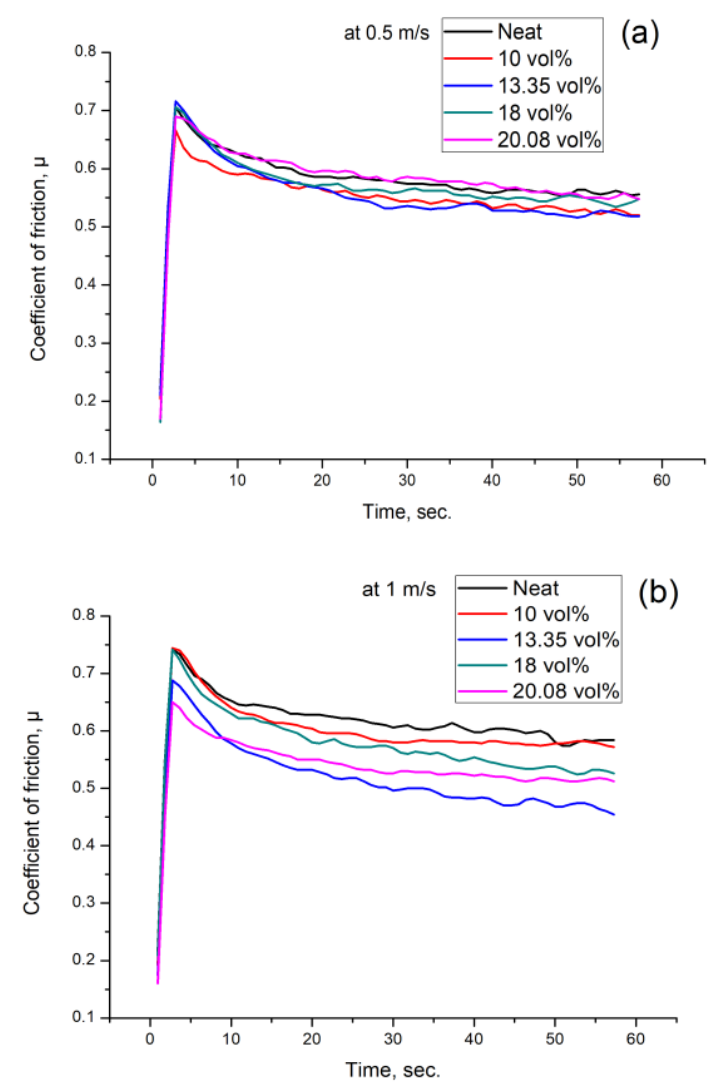

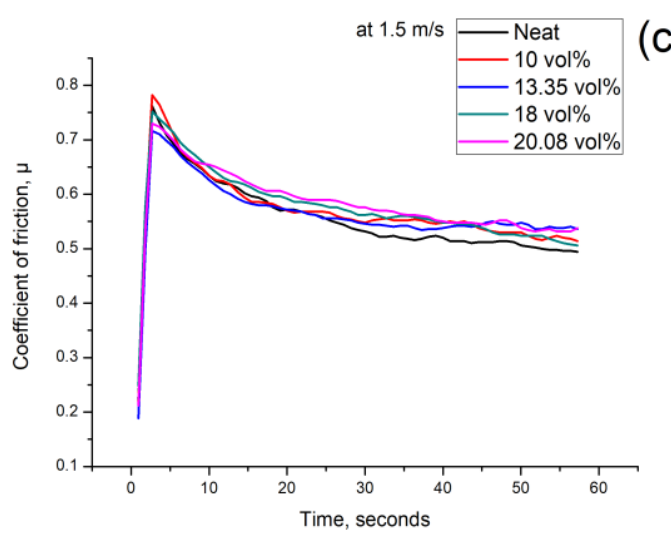

Fig 4 Coefficient of friction behaviour at (a) $0.5 \mathrm{~m} / \mathrm{s}$ (b) 1 $\mathrm{m} / \mathrm{s}(\mathrm{c}) 1.5 \mathrm{~m} / \mathrm{s}$

Table II shows an average value of friction coefficient showing the effect of fiber increment and sliding velocity.

Table 2 Coefficient of friction at different fiber wt $\%$ and sliding velocity

\begin{tabular}{lccc}
\hline Specimen & $0.5 \mathrm{~m} / \mathrm{s}$ & $1 \mathrm{~m} / \mathrm{s}$ & $1.5 \mathrm{~m} / \mathrm{s}$ \\
\hline Neat & 0.58 & 0.62 & 0.56 \\
$10 \mathrm{vol} \% \mathrm{KGF}$ & 0.55 & 0.60 & 0.57 \\
$13.35 \mathrm{vol} \% \mathrm{KGF}$ & 0.56 & 0.52 & 0.57 \\
18 vol\% KGF & 0.57 & 0.58 & 0.58 \\
20.08 vol\% KGF & 0.59 & 0.54 & 0.59 \\
\hline
\end{tabular}

The COF value at intermediate sliding velocity was found fluctuating where as an increase trend was followed with insertion of fiber amount at $0.5 \mathrm{~m} / \mathrm{s}$ and $1.5 \mathrm{~m} / \mathrm{s}$.

\section{CONCLUSION}

The influence of KGF content $(0,10,13.35,18$ and 20.08 vol\%) and the sliding velocity $(0.5 \mathrm{~m} / \mathrm{s}, 1 \mathrm{~m} / \mathrm{s}$ and $1.5 \mathrm{~m} / \mathrm{s})$ on wear and coefficient of friction behavior was studied at $5 \mathrm{~N}$ and sliding time of $60 \mathrm{sec}$. The sliding velocity greatly influence the wear behavior of kans grass composites. The specimens experienced an increase in the wear with respect to time with increase in sliding velocity. The KGF composites showed lower wear rate than the specimen containing 0 vol\% of fiber. The composite specimens at 13.35 vol. \% offered maximum wear resistance at $1 \mathrm{~m} / \mathrm{s}$ and $1.5 \mathrm{~m} / \mathrm{s}$ and the specimen contained 20.08 vol\% exhibited maximum at 0.5 $\mathrm{m} / \mathrm{s}$. After attaining the initial peaking, the slope of friction coefficient curves falled greatly with increase in sliding time. The sliding velocity and fiber content also notably influenced the coefficient of friction behaviour. More reinforcement of KGF from 10 vol\% to 20.08 vol\% slightly increased the friction coefficient of the kans grass composite specimens at low and high sliding velocity. However, at intermediate sliding velocity, the friction behaviour remained fluctuating.

\section{ACKNOWLEDGMENTS}

The authors would like to acknowledge Mechanical Engineering Department of U.I.E.T., Kurukshetra University, Kurukshetra for providing the lab testing facility. 


\section{REFERENCES}

[1] A. M. Eleiche and G. M. Amin, "The effect of unidirectional cotton fibre reinforcement on the friction and wear characteristics of polyester," Wear, vol. 112, no. 1, pp. 67-78, 1986.

[2] L. T. Drzal, A. K. Mohanty, and M. Misra, "Bio-composite materials as alternatives to petroleum-based composites for automotive applications," Magnesium, vol. 40, no. 60, pp. 1-3, 2001

[3] V. K. Thakur, M. K. Thakur, and R. K. Gupta, "raw natural fiber-based polymer composites," International Journal of Polymer Analysis and Characterization, vol. 19, no. 3, pp. 256-271, 2014.

[4] A. Nourbakhsh and A. Ashori, "Wood plastic composites from agro-waste materials: Analysis of mechanical properties," Bioresource technology, vol. 101, no. 7, pp. 2525-2528, 2010.

[5] U. Nirmal, B. F. Yousif, D. Rilling, and P. V. Brevern, "Effect of betelnut fibres treatment and contact conditions on adhesive wear and frictional performance of polyester composites," Wear, vol. 268, no. $11-12$, pp. $1354-1370,2010$

[6] J. Holbery and D. Houston, "Natural-fiber-reinforced polymer composites in automotive applications," Jom, vol. 58, no. 11, pp. 80-86, 2006.

[7] H. Ku, H. Wang, N. Pattarachaiyakoop, and M. Trada, "A review on the tensile properties of natural fiber reinforced polymer composites," Composites Part B: Engineering, vol. 42, no. 4, pp. 856-873, 2011.

[8] B. Barari et al., "Mechanical characterization of scalable cellulose nano-fiber based composites made using liquid composite molding process," Composites Part B: Engineering, vol. 84, pp. 277-284, 2016.

[9] R. A. Ibrahim, "Tribological performance of polyester composites reinforced by agricultural wastes," Tribology International, vol. 90 , pp. 463-466, 2015.

[10] C. E. Correa, S. Betancourt, A. Vázquez, and P. Gañan, "Wear resistance and friction behavior of thermoset matrix reinforced with Musaceae fiber bundles," Tribology International, vol. 87, pp. 57-64, 2015.

[11] N. A. Nordin, F. M. Yussof, S. Kasolang, Z. Salleh, and M. A. Ahmad, "Wear rate of natural fibre: long kenaf composite," Procedia Engineering, vol. 68, pp. 145-151, 2013.

[12] V. Ahlawat, A. Malik, and C. Singh, "Parametric Optimization and Wear Behavior of Fiber-Reinforced Polyester Composites," IUP Journal of Mechanical Engineering, vol. 8, no. 3, 2015.

[13] V. Ahlawat, S. Kajal, and A. Parinam, "Experimental analysis of tensile, flexural, and tribological properties of walnut shell powder/polyester composites," Euro-Mediterranean Journal for Environmental Integration, vol. 4, no. 1, p. 1, 2019.

[14] V. Ahlawat, A. Parinam, and S. Kajal, "Experimental study of tensile and flexural properties of kans grass fiber reinforced polyester composites," 2018.

[15] P. K. Bajpai, I. Singh, and J. Madaan, "Tribological behavior of natural fiber reinforced PLA composites," Wear, vol. 297, no. 1-2, pp. 829-840, 2013. experience. His area of research is Solar Air Conditioning and composites processing. Currently, he has 08 research publications in journal of national and international repute.

\section{AUTHORS PROFILE}

Mukesh Kumar Mann has completed his Ph.D. from U.I.E.T., Maharshi Dayanand University, Rohtak. He has 10 years of teaching experience. His area of research is Industrial Engineering and Composite Processing and Technology.

Vishal Ahlawat is Assistant Professor in Mechanical Engineering Department of U.I.E.T., Kurukshetra University, Kurukshetra. He has 9.5 years of teaching experience. His area of research is Tribology and Fiber Composites. Currently, he has 06 research publications in journal of national and international repute.

Sunil Nain is Assistant Professor in Mechanical Engineering Department of U.I.E.T., Kurukshetra University, Kurukshetra. He has 11 years of teaching 